\title{
Região de retirada da estaca e substrato na propagação vegetativa de roseira de vaso ${ }^{(1)}$
}

\author{
MARISTELA PEREIRA CARVALHO ZANÃO(2), LUIZ ANTÔNIO ZANÃO JÚNIOR ${ }^{(3)}$ \\ JOSÉ ANTÔNIO SARAIVA GROSSI(4), EDSON VANZELLA(5), FABÍOLA VILLA(2)
}

\begin{abstract}
RESUMO
A roseira é uma das principais espécies ornamentais produzidas no Brasil. Sua propagação é feita principalmente por estaquia. Nesse processo, estaca e substrato podem influenciar na qualidade das mudas produzidas. Diante do exposto, objetivou-se com o presente trabalho avaliar a melhor região de retirada da estaca e o substrato adequado para propagação vegetativa de roseira de vaso cv. Yellow Terrazza ${ }^{\circledR}$. O delineamento experimental utilizado foi inteiramente casualizado, em esquema fatorial $2 \times 3$ [duas regiões de retirada da estaca, apical e mediana x três substratos: substrato comercial, mistura de solo argiloso e substrato comercial $(1: 1, \mathrm{v} / \mathrm{v})$ e mistura de areia e substrato comercial $(1: 1, \mathrm{v} / \mathrm{v})]$, com dez repetições. O experimento foi conduzido em túnel coberto com tela de sombreamento. As estacas foram acondicionadas em vaso de polipropileno com capacidade de $100 \mathrm{~cm}^{3}$, preenchido com cada substrato. Avaliaram-se comprimento da maior raiz, número de raízes/estaca, produção de matéria seca de raízes e das brotações. A estaca apical propaga com maior qualidade as mudas de roseira de vaso cv. Yellow Terrazza ${ }^{\circledR}$ do que a estaca mediana, sem interação com o tipo de substrato. Os melhores resultados foram obtidos com a mistura de solo argiloso e substrato comercial. Palavras-chave: Rosa hybrida; floricultura; propagação assexuada.
\end{abstract}

\begin{abstract}
Withdrawal of region cutting and substrate in propagation vegetative pot of roseira

The rose is a major ornamental species produced in Brazil. Its propagation is mainly made by cutting. In the process, cutting and substrate can influence the quality of seedlings. Given the above, the aim of the present study was to evaluate the best cutting withdrawal region and the appropriate substrate for vegetative propagation of pot rose cv. Yellow Terrazza ${ }^{\circledR}$. The experimental design was completely randomized in a 2x3 factorial [two cutting removal of regions, apical and median $\mathrm{x}$ three substrates: commercial substrate, clay soil and commercial substrate mixture $(1: 1, \mathrm{v} / \mathrm{v})$ and sand and commercial substrate mixture $(1: 1, \mathrm{v} / \mathrm{v})]$, with ten replicates. The experiment was conducted in a tunnel covered with shadecloth.The cuttings were placed in polypropylene vase with $100 \mathrm{~cm}^{3}$ capacity, filled with each substrate. Were evaluated the length of roots, number of roots/cutting and dry matter of roots and shoots. The apical cutting propagates with higher quality seedlings of pot rose cv. Yellow Terrazza ${ }^{\circledR}$ than the median cutting, without influence of substrate type. Got better preparation of the pot rose cutting with clay soil and commercial substrate mixture.
\end{abstract}

Keywords: Rosa hybrid; floriculture; asexual propagation.

\section{INTRODUÇ̃̃O}

A roseira é uma das plantas ornamentais mais produzidas no mundo. É produzida tanto para flor de corte quanto em vasos (HASHEMABADI e ZARCHINI, 2010; ALMEIDA et al., 2014). No Brasil, é considerada a principal flor de corte produzida, tanto para o mercado interno, quanto para exportação (LANDGRAF e PAIVA, 2005; MARTINS et al., 2009).

A produção e comercialização de rosas em vasos é uma opção considerada recente para o mercado de flores e plantas ornamentais. São produzidas em viveiros modernos e o processo produtivo da produção da muda à comercialização dura em torno de 14 a 16 semanas. São classificados de acordo com o tamanho do vaso, diâmetro, densidade da planta, número de botões, maturação e cor (FCH, 2016).
Sua propagação é comumente realizada via enxertia por produtores comerciais de flores de corte, além de sementes, micropropagação e estaquia (KHAN et al., 2004; PARK e JEONG, 2012; BAYANATI e MORTAZAVI, 2013). No caso da produção, este último é o mais empregado na formação das mudas de espécies silvestres, cultivares com ascendência próxima a elas, como as trepadeiras e também para porta-enxertos empregados na enxertia (BARBOSA, 2003; PIVETTA et al., 2004). Para as roseiras destinadas ao cultivo em vaso, há poucas informações sobre o melhor método de propagação.

Na propagação por estaquia, vários fatores endógenos (genéticos e fisiológicos) e ambientais podem influenciar os resultados, conforme Pedrinho et al. (2003), Alfenas et al. (2009) e Xavier et al. (2009). A região de retirada da estaca no ramo da planta matriz e os substratos utilizados são fatores que interferem no enraizamento desta e na

(1) Recebido em 12/08/2015 e aceito em 16/02/2016

(2) Universidade Estadual do Oeste do Paraná - UNIOESTE, Departamento de Agronomia, Marechal Cândido Rondon - PR , Brasil. * Autor

correspondente: E-mail: maristelacarvalho@gmail.com

(3) Instituto Agronômico do Paraná - IAPAR, Área de Solos, Santa Tereza do Oeste - PR, Brasil.

(4) Universidade Federal de Viçosa - UFV, Departamento de Fitotecnia, Viçosa - MG, Brasil.

(5) Universidade Estadual do Oeste do Paraná - UNIOESTE, Departamento de Engenharia de Energia na Agricultura, Cascavel - PR, Brasil. 
produção de mudas (LIMA et al., 2006; LONE et al., 2010; OLIVEIRA et al., 2012; SILVA et al., 2012). O tipo de estaca mais adequado, de acordo com a região de retirada, varia com a espécie ou cultivar (GARBUIO et al., 2007; LUZ et al., 2007; PAIVA e GOMES, 2011). Como a composição do tecido diverge ao longo do ramo, estacas provenientes de diferentes porções deste, tendem a diferir quanto à porcentagem de enraizamento. Assim, estacas mais lignificadas geralmente são mais difíceis de enraizar do que estacas herbáceas e semilenhosas (FACHINELLO et al., 2005).

As regiões de crescimento, como ápice caulinar, gemas e folhas, produzem o fitoregulador endógeno, conhecido como auxina, o qual também pode ser aplicado de forma exógena. Esta substância indutora da formação de raízes pode ser abundante, escassa ou mesmo ausente no interior da planta, de acordo com a condição fisiológica e genética da estaca (HINOJOSA, 2000; HARTMANN et al., 2011).

Dentre os fatores ambientais que influenciam $O$ pegamento e enraizamento das estacas, pode-se citar o substrato, o qual exerce também grande influência na sustentação das estacas. O substrato garante a manutenção mecânica do sistema radicular e estabilidade da planta, suprimento de água e nutrientes, oxigênio e transporte de dióxido de carbono entre as raízes e o ar externo. $\mathrm{O}$ desejável é que ele seja permeável, poroso, bem drenado, livre de patógenos, pragas e propágulos de ervas daninhas e tenha baixa densidade, bem como disponibilidade e viabilidade econômica (KÄMPF, 2005), sendo que o ideal para o enraizamento depende da espécie, tamanho da estaca, época, sistema de propagação, custo e disponibilidade de seus componentes (HARTMANN et al., 2011).

Diversos materiais podem ser utilizados como substrato, bem como a mistura destes. Além disso, existem muitas opções de substratos comerciais disponíveis que atendem perfeitamente muitos desses requisitos, porém apresentam elevado custo. Uma das soluções é misturar materiais que possam ser facilmente obtidos, com o mesmo desempenho ou desempenho superior, reduzindo assim os custos de produção.

Diante do exposto, objetivou-se com o presente trabalho avaliar a melhor região de retirada da estaca e o substrato adequado para propagação vegetativa de roseira de vaso cv. Yellow Terrazza ${ }^{\circledR}$.

\section{MATERIAL E MÉTODOS}

Os tratamentos foram originados de esquema fatorial $2 \times 3$, sendo duas regiões de retirada da estaca na planta matriz (apical e mediana) e três substratos (substrato comercial, solo argiloso + substrato comercial (proporção 1:1 em volume) e areia + substrato comercial (proporção
1:1 em volume). O delineamento adotado foi o inteiramente casualizado, com dez repetições com uma estaca em cada vaso.

Plantas matrizes de roseira cv. Yellow Terrazza ${ }^{\circledR}$, com 115 dias de idade cultivadas em vaso de $600 \mathrm{~cm}^{3}$ contendo substrato comercial, foram utilizadas para retirada das estacas herbáceas, no mês de agosto. As estacas foram oriundas de hastes florais com flores em estágio de senescência, nas quais foram retiradas estacas apicais (diâmetro de $31 \mathrm{~mm}$ ) e medianas (diâmetro de $35 \mathrm{~mm}$ ), com aproximadamente $10 \mathrm{~cm}$ de comprimento, mantendose uma folha e duas gemas, sendo retirados os restos florais. Os vasos com as estacas foram mantidos durante duas semanas em túnel coberto com tela de sombreamento (60 \%) e irrigação com nebulização intermitente de água de 15 em 15 minutos. Após este período, a irrigação por aspersão foi cessada, realizando a irrigação manual diariamente.

Utilizaram-se como recipientes vasos de polipropileno com capacidade de $100 \mathrm{~cm}^{3}$, preenchidos com os respectivos substratos. O solo argiloso foi coletado na profundidade de 0-20 $\mathrm{cm}$, apresentando teores de $\mathrm{Ca}$ (3 $\left.\mathrm{cmol}_{\mathrm{c}} \mathrm{dm}^{-3}\right), \mathrm{Mg}\left(1 \mathrm{cmol}_{\mathrm{c}} \mathrm{dm}^{-3}\right), \mathrm{K}\left(0,8 \mathrm{cmol}_{\mathrm{c}} \mathrm{dm}^{-3}\right), \mathrm{P}(40$

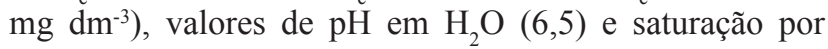
bases $(80 \%)$ classificados como bons para a cultura da roseira (ALVAREZ et al., 1999) e teor de argila de $60 \%$. A areia utilizada foi lavada, esterilizada, apresentando como característica granulométrica textura média. O substrato comercial utilizado foi o Plantmax $^{\circledR}$, a base de casca de pinus.

Após 70 dias de estaqueamento, avaliaram-se o comprimento da maior raiz $(\mathrm{cm})$, com auxílio de um paquímetro digital e o número médio de raízes por estaca. A produção de matéria seca das raízes e brotações (mg planta $^{-1}$ ) foi determinada separando-as e lavando com água destilada, através de secagem em estufa de circulação forçada de ar, a $65{ }^{\circ} \mathrm{C}$ até massa constante, pesadas em balança analítica.

Os dados foram submetidos à análise de variância, sendo as médias comparadas pelo teste de Tukey, a $5 \%$ de probabilidade de erro.

\section{RESULTADOS E DISCUSSÃO}

De acordo com a análise de variância, verificou-se diferença significativa para todas as variáveis analisadas, em função da região de retirada da estaca e substrato utilizado, mas não foi verificada interação entres esses fatores.

Na Tabela 1 observam-se o comprimento da maior raiz, número médio de raízes/estaca e produção de matéria seca das raízes e brotações de roseira de vaso, sendo estas variáveis maiores quando foram utilizadas estacas apicais. 
Tabela 1. Comprimento da maior raiz (CMR), número de raízes/estaca (NRE), produção de matéria seca de raízes (PMSR) e produção e matéria seca das brotações (PMSB) de roseira de vaso (cv. YellowTerrazza ${ }^{\circledR}$ ), em função da região de retirada das estacas na planta matriz.

Table 1. Longest root length (CMR), number of roots/cutting (NRE), dry matter production of roots (PMSR) and dry matter production of shoots (PMSB) of poted roses (cv. Yellow Terrazza ${ }^{\circledR}$ ) in function of the location cuttings taken from the mother plant.

\begin{tabular}{|c|c|c|c|c|}
\hline Região de retirada das estacas & $\begin{array}{c}\text { CMR } \\
(\mathrm{cm})\end{array}$ & NRE & $\begin{array}{c}\text { PMSR } \\
(\mathrm{g} \mathrm{planta})\end{array}$ & $\begin{array}{c}\text { PMSB } \\
\left(\mathrm{g} \text { planta }^{-1}\right)\end{array}$ \\
\hline Estacas apicais & $4,85 \mathrm{a}$ & $12,6 \mathrm{a}$ & $0,182 \mathrm{a}$ & $0,054 \mathrm{a}$ \\
\hline Estacas medianas & $4,41 \mathrm{~b}$ & $10,3 \mathrm{~b}$ & $0,148 \mathrm{~b}$ & $0,041 \mathrm{~b}$ \\
\hline CV (\%) & 6,73 & 8,67 & 8,73 & 4,31 \\
\hline
\end{tabular}

Médias seguidas de letras minúsculas na coluna, diferem entre si, pelo teste de Tukey, a 5\% de probabilidade de erro.

Estacas apicais proporcionaram raízes mais desenvolvidas quanto ao comprimento, $10 \%$ superior em relação às estacas medianas. Também se destacaram em relação as número de raízes, com $22 \%$ a mais do que as medianas. Em relação à produção de matéria seca de raízes, as estacas apicais foram $23 \%$ superiores, em comparação às estacas medianas. Estes melhores resultados obtidos com estacas apicais podem ser atribuídos ao menor grau de lignificação desses tecidos, menor quantidade de compostos fenólicos e maior capacidade de retomar a condição meristemática, fundamental para a iniciação radicular (STUMPF et al., 2001; HARTMANN et al., 2011).

Estudos sobre propagação assexuada em floricultura são escassos, principalmente em relação à estaquia. Martins et al. (2001), estudando a propagação vegetativa de jambeiro rosa (Syzigium malacensis), verificaram maior enraizamento de estacas utilizando as apicais. Este maior enraizamento também foi observado por Garbuio et al. (2007), estudando mudas de patchouli (Pogostemon cablin). O maior enraizamento obtido nas estacas apicais pode ser creditado à sua proximidade com os locais de síntese de auxinas e cofatores de enraizamento, que se deslocam destes locais de síntese (ápices meristemáticos e folhas jovens) até a base, onde produzem efeito para a emissão de raízes (DUTRA et al., 2002).

Na Tabela 2 verificam-se os resultados para comprimento da maior raiz, número de raízes/estaca, produção de matéria seca de raízes e brotações, com melhores resultados para estas quatro variáveis quando empregado o substrato comercial associado ao solo ou à areia.

Tabela 2. Comprimento da maior raiz (CMR), número de raízes/estaca (NRE), produção de matéria seca de raízes (PMSR) e produção de matéria seca das brotações (PMSB) de roseira de vaso (cv. YellowTerrazza ${ }^{\circledR}$ ), em função dos substratos. Table 2. Longest root length (CMR), number of roots / cutting (NRE), dry matter production of roots (PMSR) and dry matter production of shoots (PMSB) of poted rose (cv. YellowTerrazza ${ }^{\circledR}$ ) in function of the substrates.

\begin{tabular}{|c|c|c|c|c|}
\hline Substratos & $\begin{array}{c}\text { CMR } \\
(\mathrm{cm})\end{array}$ & NRE & $\begin{array}{c}\text { PMSR } \\
\left(\text { g planta }^{-1}\right)\end{array}$ & $\begin{array}{c}\text { PMSB } \\
\left.(\mathrm{g} \mathrm{planta})^{-1}\right)\end{array}$ \\
\hline Substrato comercial & $4,38 \mathrm{~b}$ & $11,1 \mathrm{~b}$ & $0,168 \mathrm{~b}$ & $0,053 \mathrm{a}$ \\
\hline Solo argiloso + Substrato comercial & $4,61 \mathrm{a}$ & $14,3 \mathrm{a}$ & $0,138 \mathrm{c}$ & $0,054 \mathrm{a}$ \\
\hline Areia + Substrato comercial & $4,43 \mathrm{~b}$ & $9,1 \mathrm{c}$ & $0,190 \mathrm{a}$ & $0,036 \mathrm{~b}$ \\
\hline CV\% & 9,73 & 8,67 & 8,73 & 4,31 \\
\hline
\end{tabular}

Médias seguidas de letras minúsculas na coluna, diferem entre si, pelo teste de Tukey, a 5\% de probabilidade de erro.

O número de raízes formadas/estaca utilizando a mistura solo argiloso + substrato comercial foi $29 \%$ maior que os proporcionados pelo substrato comercial e $57 \%$ que os proporcionados pela mistura areia + substrato comercial. Uma maior quantidade de raízes/estaca significa maior absorção de água e nutrientes, fator determinante para o bom desenvolvimento da muda após o plantio. Além disso, uma mistura do solo com substrato comercial reduz os custos na produção de mudas de espécies floríferas. Além disso, foi visualmente perceptível que em relação à agregação do substrato às raízes (formação de torrão), o solo argiloso proporcionou melhor agregação do que os outros. Essa característica é muito importante no plantio, tendo em vista que, para um bom estabelecimento da muda, é essencial que esta não sofra danos no sistema radicular, o que pode ser evitado ou minimizado, mediante substratos que proporcionem boa agregação às raízes, formando um torrão (KÄMPF, 2005).

Embora a mistura solo + substrato comercial tenha possibilitado a produção de maior número de raízes formadas e comprimento médio das raízes, a produção de matéria seca destas raízes foi mais baixa dentre as três 
composições de substrato avaliadas. Entretanto, como observado na Tabela 2, a menor produção de matéria seca de raízes não influenciou a produção de matéria seca das brotações. Assim, as raízes, apesar de mais leves, foram produzidas em maior número e com maior comprimento da raiz mais desenvolvida.

Verificou-se maior produção de matéria seca de raízes com a utilização da mistura areia + substrato comercial (Tabela 2). A areia apresenta alta densidade, drenagem rápida e eficiente, características desejáveis na produção de mudas floríferas (KÄMPF, 2005). Porém, de acordo com a espécie e tempo que essas mudas permanecem nos recipientes até serem transplantadas, o substrato contendo areia pode não ser adequado. Segundo Hartmann et al. (2011), a areia tem o inconveniente de produzir sistema radicular não ramificado e mais frágil. Entretanto, Lima et al. (2007) verificaram que o melhor substrato foi a areia, para o enraizamento de estacas de jambolão, que não tolera substrato e ambiente encharcados. No caso da roseira de vaso, a mistura de areia + substrato comercial reduziu a qualidade da muda produzida, com menor quantidade de raízes e menor produção de matéria seca das brotações.

\section{CONCLUSÕES}

A utilização de estacas apicais e mistura de solo argiloso e substrato comercial como substrato, resultaram em melhor propagação das mudas de roseira de vaso cv. Yellow Terrazza ${ }^{\circledR}$.

\section{REFERÊNCIAS}

ALFENAS, A. C.; ZAUZA, E.A. V.; MAFIA, R. G.;ASSIS, T. F. Clonagem e doenças do eucalipto. Viçosa, MG: UFV, 2009. 500 p.

ALMEIDA, E. F. A.; PIVETTA, K. F. L.; PAIVA, P. D. O.; ICHINOSE, J. G. S.; GIMENES, R.; LESSA, M. A.; REIS, S. N.; CARVALHO, L. M.; RIBEIRO, M. N. O. Rosa. In:Produção de Flores de Corte. Lavras: Editora UFLA, v.2, 2014. 819p.

ALVAREZ V., V. H.; NOVAIS, R. F.; BARROS, N. F.; CATARUTTI, R. B.; LOPES, A. S. Interpretação dos resultados das análises de solos. In: RIBEIRO, A.C.; GUIMARÃES, P. T. G.; AlVAREZ V., V. H. Recomendações para o uso de corretivos e fertilizantes em Minas Gerais: $5^{\text {a }}$ Aproximação. Viçosa: Comissão de Fertilidade do Solo do Estado de Minas Gerais, 1999. p.2532.

BARBOSA, J. G. Produção comercial de rosas. Viçosa: Aprenda Fácil, 2003. 200p.

BAYANATI, M.; MORTAZAVI, S. N. Micropropagation from cultured nodal explants of Rosa hybrida cv. 'Black Bacara'. International Journal of Agronomy and Plant Production, Turkey, v.4, n.6, p.1381-1385.
DUTRA, L. F.; KERSTEN, E.; FACHINELLO, J. C. Época de coleta, ácido indolbutírico e triptofano no enraizamento de estacas de pessegueiro. Scientia Agricola, Piracicaba, v.59, n.2, p.327-333, 2002.

FACHINELLO, J. C.; HOFFMANN, A.; NACHTIGAL, J. C. Propagação de plantas frutíferas. Brasília: Embrapa Informação Tecnológica, 2005. 221p.

FLOWER COUNCIL OF HOLLAND. 2016. July 2016: potted rose is houseplant of the month. Disponível em: http://www.flowercouncil.co.uk/campaign/july-2016potted-rose-is-houseplant-of-the-month. Acesso em 13 de fevereiro de 2016 .

GARBUIO, C.; BIASI, L. A.; KOWALSKI, A. P. J.; SIGNOR, D.; MACHADO, E. M.; DESCHAMPS, C. Propagação por estaquia em patchouli com diferentes números de folhas e tipos de estacas. Scientia Agraria, Curitiba, v.8, n.4, p.435-438, 2007.

HARTMANN, H. T.; KESTER, D. E.; DAVIES JR., F. T..; GENEVE, R. L. Plant propagation: principles and practices. 8ed. Boston: Prentice-Hall, 2011. 915 p.

HASHEMABADI, D.; ZARCHINI, M. Yeild and quality management of rose (Rosa hybrida cv. Poison) with plant growth regulators. Plant Omics Journal, Lismore, v.3, n.6, p.167-171, 2010.

HINOJOSA, G. F. Auxinas. In: CID, L. P. B. Introdução aos hormônios vegetais. Brasília: Embrapa, 2000. p.1554.

KÄMPF, A. N. Substrato. In: KAMPF, A. N. Produção comercial de plantas ornamentais. 2. ed. Guaíba: Agrolivros, 2005. p. 45 - 72.

KHAN, M. A.; ZIAF, K., AHMAD, I. Effect of various hormones and diferente rootstocks and rose propagation. Pakistan Journal of Biological Sciences, Faisalabad, v.7, n.10, p. 1643-1646, 2004.

LANDGRAF, P. R. C.; PAIVA, P. D. O. Produção e comercialização de flores em Minas Gerais. Informe Agropecuário, Belo Horizonte, v.26, n.227, p.7-11, 2005.

LIMA, R. L. S.; SIQUEIRA, D. L.; WEBER, O. B.; CAZZETA, J. O. Comprimento de estacas e parte do ramo na formação de mudas de aceroleira. Revista Brasileira Fruticultura, Jaboticabal, v.28, n.1, p.83-86, 2006.

LIMA, Y. O. U.; RITTER, M.; ALCÂNTARA, G. B.; LIMA, D. M.; FOGAÇA, L. A.; QUOIRIN, M.; CUQUEL, F. L.; BIASI, L. A. Tipos de estacas e substratos no enraizamento de jambolão. Scientia Agraria, Curitiba, v.8, n.4, p.449-453, 2007. 
LONE, A. B.; LÓPEZ, E. L.; ROVARIS, S. R. S.; KLESENER, D. F.; HIGASHIBARA, L.; ATAÍDE, L. T.; ROBERTO, S. R. Efeito do AIB no enraizamento de estacas herbáceas do porta-enxerto de videira VR 4343 em diferentes substratos. Semina Ciências Agrárias, Londrina, v.31, n.3, p.599- 604. 2010

LUZ, P. B.; PAIVA, P. D. O.; LANDGRAF, P. R. C. Influência de diferentes tipos de estacas e substratos na propagação assexuada de hortênsia [Hydrangea macrophylla (Thunb.) Ser.] Ciência e Agrotecnologia Lavras, v.31, n.3, p.699703, 2007.

MARTINS, A. B. G.; GRACIANO, F. A.; SILVA, A. V. C. Clonagem de jambeiro rosa (Syzigium malacensis) por estaquia de ramos enfolhados. Revista Brasileira de Fruticultura, Jaboticabal, v.23, n.2, p.365-368, 2001.

MARTINS, M. V. M.; ANDRIGUETO, J. R.; VAZ, A. P. A.; MOSCA, J. L. Produção Integrada de Flores no Brasil. Informe Agropecuário, Belo Horizonte, v.30, n.249, p.6466, 2009

OLIVEIRA, Y.; LOPES, V. R.; SOUZA, S.; ZUFFELLATORIBAS, K. C.; NERY, F. S. G.; KEPPEN, S. C. Influência do ácido indol butírico e de diferentes alturas de coleta de estacas apicais no enraizamento de Melaleuca arternifolia [Maiden \& Betche] Cheel. Revista Brasileira de Agrociência, Pelotas, v.18 n.2-4, p.196-203, 2012.

PAIVA, H. N.; GOMES, J. M. Propagação vegetativa de espécies florestais. 1 ed. Viçosa:UFV, 2011, 52p.
PARK, Y. G.; JEONG, B. R. Effect of light intensity during stenting propagation on rooting and subsequent growth of two rose cultivars. Flower Research Journal, Seul, v.20, n.4, p.228-232, 2012.

PEDRINHO, D. R.; PIVETTA, K. F. L.; PIZETTA, P. U. C.; CASALLI, L. P.; SARZI, I. Efeito do armazenamento de estacas no enraizamento de roseiras para corte nas quatro estações do ano. Revista Brasileira de Horticultura Ornamental, Campinas, v.9, n.1, p.25-30, 2003.

PIVETTA, K. F. L.; PIZETTA, P. U. C.; PEDRINHO, D. R. Morphologic characterization and evaluation of the productivity of nine rootstocks of rose bush (Rosa sp.). Acta Horticulturae, Leuven, v.630, p.213-217, 2004.

SILVA, R. C. P.; MAIA, S. S. S.; PAIVA, E. P.; SILVA, A. C.; COELHO, M. F. B.; SILVA, F. N. Efeito da composição de substratos no enraizamento de estacas de Hyptis suaveolens (L.). Revista Brasileira de Ciências Agrárias, Recife, v.7, n.2, p.219-225, 2012.

STUMPF, E. R. T.; GROLLI, P. R.; SCZEPANSKI, P. H. G. Efeito do ácido indolbutírico, substrato e tipo de estaca no enraizamento de Chamaecyparis lawsoniana Parl. Revista Brasileira de Agrociência, Porto Alegre, v.7, n.2, p.101-105, 2001.

XAVIER, A.; WENDLING, I.; SILVA, R. L. Silvicultura clonal: princípios e técnicas. Viçosa: UFV, 2009. 272 p. 